\title{
Foster $v$ Jessen: a comment on law and online defamation in Northern Ireland
}

\author{
Mark Patrick Hanna \\ Queen's University Belfast \\ Correspondence email: mark.hanna@qub.ac.uk
}

\section{INTRODUCTION}

W ith a national television celebrity being hauled before a Belfast court for a false and defamatory tweet about Northern Ireland's then First Minister, Foster $v$ Jessen was always going to prove good copy for the press. ${ }^{1}$ For lawyers and legal academics, however, the case appeared relatively straightforward and of little significance to this notoriously complex area of law. The inherently serious nature of the defamatory tweet, the lack of any proper response or likely defence, and the way in which the application for the defendant's late appearance consumed the court in analysis of facts, meant that the case contained no great contest of legal principle. Nonetheless, the case invites some brief reflection on certain issues in defamation law in Northern Ireland today.

\section{BACKGROUND}

The plaintiff, Arlene Foster, was elected leader of the Democratic Unionist Party (DUP) in 2015 and served as First Minister of Northern Ireland from January 2016 until the collapse of the Northern Ireland Executive a year later. At the material time, late December 2019, she was involved in difficult negotiations to restore authority to the Northern Ireland Executive - although, with the Christmas holidays having just begun, one can easily imagine that she was looking forward to spending some time with her family, away from public life.

The defendant, Christian Jessen, is a practising doctor, who worked for a number of years at a clinic at Harley Street, London, but is more widely known as a presenter on popular television shows such as Embarrassing Bodies or Supersize vs Super Skinny. On the evening of 23 December 2019, the defendant posted a tweet to his 311,000 followers on Twitter about 'rumours' that Mrs Foster was having an extra-marital affair, with further comments about a perceived hypocrisy 
of 'preaching the sanctity of marriage' and implying the plaintiff was homophobic. ${ }^{2}$

The defendant was not the original source of the rumour on the internet, but, with the help of his tweet, the rumour percolated further through the social media grapevine, with other users 'liking' or retweeting the post (by 6 January 2020, the defendant's original tweet had been retweeted 517 times and had been liked by approximately 3500 users). ${ }^{3}$ The plaintiff was informed of the defendant's tweet on the evening it had been posted, and the next morning contacted her solicitor, Paul Tweed, instructing him to take appropriate action. Mr Tweed, at first, apparently had some difficulty finding an address at which to contact the defendant, and on 24 December 2019 instead posted a response on the defendant's Twitter page, putting the defendant on notice in relation to the false allegation and promising that 'legal action will also be taken against any person' who retweeted the allegation.

Unfortunately (not least for the defendant), this had something of a so-called 'Streisand effect', namely where an attempt to censor information has the adverse effect of publicising it further. When one other Twitter user pointed this out, the defendant appeared to celebrate that Mr Tweed's post was having such a 'Streisand effect'.

Thereafter, correspondence between the parties withdrew to more private channels, although it was largely one-sided, issuing mostly from the plaintiff, with little response from the defendant. On 2 January 2020, Mr Tweed issued a letter of claim to the defendant, requiring removal of the defamatory statement, publication of a retraction and apology, and proposals to compensate the plaintiff. The defendant responded to this on 7 January 2020, confirming that the offending tweet had been removed from his Twitter page, and hoping that this would be enough to 'resolve the matter'. Obviously, it was not, and Mr Tweed posted again the outstanding requests to the defendant on 9 January 2020. There was no response to this, or to any of the other 10 subsequent letters or emails that $\mathrm{Mr}$ Tweed sent the defendant.

A writ of summons was issued on 28 January 2020, which appears to have been duly served on the defendant at his London address on 4 February 2020.4 When no appearance was entered by or on behalf of the defendant, the plaintiff issued an application to mark the judgment in default, which was granted on 29 September 2020. Even with this,

2 Whilst the DUP is broadly perceived to harbour homophobic attitudes, in her evidence, the plaintiff denied having any such negative attitudes, ibid [36].

3 Ibid [7].

4 This was a matter of some dispute, with the defendant asserting that he never received such documents or having notice of the proceedings, see below. 
there was still no answer from the defendant. The plaintiff applied for assessment of damages by judge alone and the hearing was carried out before McAlinden $\mathrm{J}$ on 14 April 2021. The plaintiff appeared to give evidence and was represented by counsel, but there was still no appearance by or on behalf of the defendant. The judge reserved a decision on damages and undertook to provide a full and reasoned judgment in due course.

All of a sudden, on Friday, 16 April 2021, two days after the hearing on damages, the court office was contacted by Olivia O'Kane of Carson McDowell, informing them she had been instructed by the defendant 'late' on 15 April 2021.5 The defendant, it was stated, had been unaware of the proceedings and now wished to respond. On 19 April 2021, an application was made by the defendant to enter a late appearance. The defendant submitted affidavits and appeared in court to give evidence in support of the application on 23 April 2021.

\section{THE COURT'S DECISION ON APPLICATION FOR DEFENDANT'S LATE APPEARANCE AND ASSESSMENT OF DAMAGES}

Much of McAlinden J's decision of 27 May 2021 is taken up with careful consideration of evidence submitted in support of the defendant's application to enter a late appearance. Leave for such could only be granted if the court could be persuaded that the defendant had in good faith been unaware of the ongoing proceedings in the case.

The court was therefore compelled to trawl through and weigh up the body of evidence presented by the defendant as explaining his ignorance of the proceedings. The exercise revealed the extent to which all our lives are now extensively documented in data and, ironically, proved some compromise to the defendant's own dignitary interests. If the defendant had really moved in to a spare room in his parents' house, how did he acquire the photos he posted on his twitter account of graffiti on a wall near his own apartment? ${ }^{6}$ If the defendant had thought court proceedings were suspended due to the COVID pandemic, how could he not have seen the extensive media coverage about Johnny Depp's own libel case in London at the time, when his own Twitter account suggested he was still following the news? ${ }^{7}$ If the defendant was suffering from mental health issues, why did he not mention these in the podcasts he appeared on discussing the subject? 8 
Did he really make up earlier stories about face-timing lonely friends during lockdown and playing virtual ping-pong with his partner for 'entertainment' value? 9

The court considered the evidence from different angles, but in the end was not convinced by the defendant's claims. The evidence was judged to point towards effective service of the key documents in the case, and that the defendant simply chose to ignore the proceedings in the hope they would go away. His application for late appearance was, therefore, refused.10

Turning to the question of assessment of damages, the court found more assurancein legislation, precedent and established legal principles. It relied heavily in that regard on the 'recent' decision of Stephens J in Elliot $v$ Flanagan. ${ }^{11}$ As there, the starting point was section 3(5) of the Defamation Act 1996 and the three declared functions of damages in defamation of 'consolation to the plaintiff', 'repair' of the damage to reputation and 'vindication'. 12 As in Elliot, reference was made to the checklist of Jones $v$ Pollard, 13 including the objective features of the libel, the subjective effect on the plaintiff; and matters tending to mitigate. ${ }^{14}$ As in Elliot, there was a nod to article 10 of the European Convention on Human Rights, and the necessity to avoid any award that disproportionately violates the defendant's right to freedom of expression. Interestingly, though, this was more emphatically ruled out as an issue in Foster, as it was considered 'not unreasonable to assume that a media figure with [the defendant's] profile ... would have substantial resources'. 15 This sat in some awkward juxtaposition with the admission a few paragraphs later that there had been "earlier anonymous tweets which had been circulating in the "twittersphere" for a number of days before the defendant's tweet was published'. ${ }^{16}$

Applying the law to the case, the judge went through the checklist. The objective features of the libel were such to accuse the plaintiff of being 'an adulterer, a hypocrite, and a homophobe'. ${ }^{17}$ It 'affected core aspects of the plaintiff's life, namely her relationship with her husband and her Christian faith'. ${ }^{18}$ It 'called into question the plaintiff's fitness

9 Ibid [71].

10 Ibid [90].

11 [2016] NIQB 8.

12 Foster $v$ Jessen (n 1 above) [91].

13 [1996] EWCA Civ 1186.

14 Foster $v$ Jessen (n 1 above) [92].

15 Ibid [97].

16 Ibid [102].

17 Ibid [103]. Though it was not contested, the plaintiff's assertion of the defamatory meaning was accepted already as such at [38].

Ibid [103]. 
and suitability to occupy the office of First Minister' at a pivotal point in the development of the office. It was a 'highly prominent libel', with wide circulation, remaining on the defendant's Twitter page for two weeks, and the subject of substantial media coverage, especially in Northern Ireland. 19

The court held the defamatory tweet caused the plaintiff 'considerable upset, distress, humiliation, embarrassment and hurt',20 and noted that the defendant took little action to mitigate the damage caused. While the tweet was eventually taken down two weeks after posting, the court emphasised the lack of apology or retraction, and that the defendant made no attempt to address compensation to the plaintiff. ${ }^{21}$ McAlinden $J$ considered the absence of an apology meant the need for vindication remains unaddressed'22 and deemed it therefore 'necessary' to make an award 'sufficient to convince a bystander of the baselessness of the charge'.23

Consulting the Green Book, the judge noted the range of compensation for loss of one eye as between $£ 80,000$ and $£ 140,000$, damages for female infertility up to $£ 150,000$ : 'Bladder, complete loss of natural function and control: $£ 125,000-£ 170,000$. Total or effective loss of one hand: $£ 85,000-£ 145,000$. Amputation of 1 foot: $£ 150,000-£ 250,000$.'24 On that basis, the court awarded the plaintiff $£ 125,000$ and costs.

\section{DISCUSSION}

The award has been reported in the press as setting a new 'UK record for defamation', 25 but it clearly is not the first award of this kind. ${ }^{26}$ It is also generally in keeping with the relatively high awards for defamation in Northern Ireland. 27 Reputation holds great importance in Northern

19 Ibid [105].

20 Ibid.

21 Ibid [107].

22 Ibid [108].

23 Ibid.

24 Ibid [110].

25 David Blevins, 'Embarrassing Bodies' Dr Christian Jessen ordered to pay Arlene Foster $£ 125,000$ over defamatory tweet' (Sky News, 27 May 2021)

26 See eg Monroe v Hopkins [2017] EWHC 433 (QB).

27 See on this Elliot $v$ Flanagan (n 11 above) [32]. As in Elliot ([33]) there was reference in Foster to conventional personal injury awards as a 'check' on any excess ([100]-[101]). However, the judgment in Elliot $v$ Flanagan was a little more careful not to make any comparison between defamation and personal injury. In Jones $v$ Pollard itself (n 13 above), Hirst LJ noted the problems with comparing harm to reputation with personal injury and noted key distinctions (257). 
Ireland. This was a senior politician, defamed by a statement which had no basis in fact, and which served no public interest.

One aspect of the decision on the assessment of damages that is worth discussing, however, is the role of vindication in damages in a case of this kind. It is an established principle that damages in defamation law can function to vindicate the reputation of the plaintiff. But it is also well recognised that the greater significance of the principle lies in those cases 'where the defendant asserts the truth of the libel'.28 Vindication is necessary where the 'truth of the statement' is in issue, ${ }^{29}$ that is, where the defendant asserts the defence of truth and where there is a need to therefore contest the truth of the allegation and set the record straight.

In addressing the effect that a dismissal of a defence of truth would have on determining damages in a defamation case, in Purnell $v$ Business F1 Magazine Ltd, Laws LJ said:

Where there has been a fiercely contested trial on the facts, perhaps attended with much publicity, and the defendant's witnesses have been roundly disbelieved and there is an unequivocal finding in the claimant's favour on the merits, those circumstances will be relevant as amounting to some vindication. 30

It is for this reason that the principle of vindication is said to be a 'factspecific question'. 31

The case of Turley $v$ Unite the Union and Stephen Walker 32 provides a good example of facts that warrant the application of vindication to damages in relation to a defamatory statement made on social media. The claimant there, Anna Turley, was a Labour Party MP, known to be opposed to Jeremy Corbyn's leadership of the party. She joined Unite to acquire a vote against its leader, Len McCluskey, in an apparent bid to undermine Mr Corbyn's support. The defendant was the author of a blog, Squawkbox, which published an allegation that the claimant had dishonestly declared she was 'unemployed' when she joined the union in order to take advantage of a discount the union offered unemployed members. In answer to the claimant's claim for defamation, the defendant asserted the defence of truth. The question that therefore had to be tried in Turley was the knowledge and intention of the claimant in joining Unite at the discounted fee for unemployed members. When

28 As per Sir Thomas Bingham MR in John v MGN [1997] QB 586, 607-608.

29 A Mullis, R Parkes and G Busutill, Gatley on Libel and Slander 12th edn (Sweet \& Maxwell 2013) para 9.1.

30 [2007] EWCA Civ 744 [29].

31 See Turley $v$ Unite the Union and Stephen Walker [2019] EWHC 3547 (QB) [32]: 'There will be occasions when the judgment will provide sufficient vindication, but whether it does so is always a fact-specific question.' Ibid. 
the evidence was considered in the whole, and it was determined to have been an innocent mistake on the part of the claimant and the defence of truth was therefore found lacking, there was a pressing need for vindication of the claimant.

The facts are quite different in Foster $v$ Jessen, however, and one might question the decision that need for vindication remained 'unaddressed' at the end of the trial. In this case, there was no question about the truth of the defamatory statement. Rather, it was the credibility of the defendant which was under close scrutiny in the case. Moreover this scrutiny was attended with a great degree of publicity, and in the end the defendant was very roundly disbelieved with an unequivocal finding in the plaintiff's favour.

There was also an important difference in the nature and form of the media in the two cases. In Turley, the defamatory statement was published on a blog devoted to discussion of such political issues, and which had enough of a loyal readership that it had a sufficient presumption of credibility amongst its readers. Posts of 'rumours' on social media, however, are quite different. It is now generally recognised that social media like Facebook and Twitter, as much as they may achieve anything else, have provided an unchecked mass medium for 'trolls', malicious falsehoods and 'fake news'. It is even widely recognised that because of these developments we now live in something of a 'post-truth' society. Most reasonable people today have a healthy degree of scepticism about statements made by individuals on social media, regardless of how well known they may be, or how many 'followers' they may have. How far, therefore, does one need to convince the reasonable bystander of the 'baselessness' of rumours posted on social media on a daily basis?

Is there even a possibility of full vindication under the conditions of social media? In the past, before the internet and social media, there were fewer sources of defamatory statements. All the offending parties could be named as defendants and summoned to set the record straight. Now, with social media, narratives circulate in 'echo chambers' and 'filter bubbles', relatively unperturbed by the counter-narratives of central authorities. Typically, there is a constellation of different sources of a single libel. In many cases, as in this (but not in Turley), the named defendant will not even be the original source of the false and defamatory statement. The application of the traditional principle of vindication to these conditions raises awkward questions about why certain defendants are singled out and how their sole liability serves as vindication.

None of this is to say the defendant in such cases should be absolved of liability for defamatory statements. The courts must do what they can to promote accountability and responsible use of social media, and 
it is accepted that a defendant's lack of credibility is no defence to an action in defamation. ${ }^{33}$ Furthermore, none of this is to say that the plaintiff in Foster $v$ Jessen did not deserve adequate compensation for the harm suffered. It cannot be doubted that, even if right-thinking members of society treated the defendant's statement in this case with scepticism, it would still have caused the plaintiff considerable distress and required setting the record straight to some degree. No one can doubt that, even if those close to the plaintiff would have given little weight to such statements on social media, the plaintiff would still have been burdened with the unpleasant responsibility of making those close to her aware that such a defamatory statement had been posted on Twitter, and with assuring them that their scepticism of such rumours was well placed.

The point about the role of vindication in damages for a defamation claim is a subtle one, but one, nonetheless, worth noting in relation to changes in the form of defamatory statements on social media. Considering the traditional role of vindication as an answer to the defendant's assertion of truth, the principle should have more nuanced and fact-specific application to those cases where the defendant contests the truth of the statement, or at least enjoys a greater degree of credibility.

Finally, even though a threshold test was not in issue in the case, it is worth making a brief point about the limited effect that a 'serious harm test' (as reflected in section 1 of the Defamation Act 2013 and section 1 of the Defamation and Malicious Publication (Scotland) Act 2021) would have in a case such as this. As the Northern Ireland Assembly is now tasked with considering reform of this area of law, 34 it may be feared by some that a serious harm test would tip the scales too far in favour of the defendant in defamation actions and leave plaintiffs in Northern Ireland without proper remedy against the increasing amount of defamatory statements which, as in this case, find platform now on social media. However, Foster $v$ Jessen reveals that, while the serious harm test may have achieved some raising of the threshold, it nonetheless would still provide ample protection for plaintiffs in such cases.

33 See Warby J in Doyle $v$ Smith [2018] EWHC 2935 (QB) [122]: 'This is an inherently odd argument, as it presupposes that people opt to read material which they do not consider credible.' Of course, the matter is somewhat different with Twitter. Users do not necessarily follow other users in the same sense that they would subscribe to readership of a publication, even including blogs that repeatedly address specific issues, and which hold themselves out as be some kind of an authority on the subject.

34 'Defamation laws could be brought in line with England by next year' (Irish Legal News, 8 June 2021). 
It is now clear that the serious harm test, as it applies in England and Wales, must be determined by reference to actual facts, and calls for investigation of the actual impact of the defamatory statement. 35 That is, damage to reputation can no longer be presumed from words alone. Nonetheless, a claim will not necessarily fail for want of evidence, and inferences of fact as to the seriousness of the harm to reputation may still be drawn from the evidence as a whole. ${ }^{36}$ In Lachaux, serious harm was proved based on a combination of the meaning of the words, the situation of the claimant, the circumstances of the publication and the inherent probabilities of harm.

The above point about the need for a more nuanced and fact-specific application of the vindication principle in assessment of damages is quite separate from this issue of serious harm. There is nothing to suggest that the plaintiff in Foster $v$ Jessen would have failed to pass the serious harm test. Had it been in issue in the case, the plaintiff may not have been required to provide any more evidence than she did at the hearing on the assessment of damages, and it should also be noted that a great deal of evidence of serious harm was considered in answering the defendant's application for late appearance. 37 If the serious harm test was applicable, and the proeceedings had reached that stage, it is nonetheless clear that, as in Lachaux, serious harm would have likely been proved based on a combination of the meaning of the words, the situation of the plaintiff in the case, the circumstances of the publication, and the inherent probabilities of harm to reputation resulting from such a statement.

On analysis, it would seem that, while the application of a serious harm test in Northern Ireland would raise the threshold slightly, it would have little effect on cases such as this. ${ }^{38}$ As a demonstration

35 Lachaux $v$ Independent Print Ltd [2019] UKSC 27, [2020] AC 612 [15].

36 Ibid [21].

37 The judge in Foster did briefly address defamatory meaning at [38]. In relation to $\mathrm{s} 1$, it should also be noted that there is scope for application of the serious harm test at a preliminary stage, if it is expedient to do so: see eg Sakho $v$ World Anti-Doping Agency [2020] EMLR 14. However, that would of course depend on abolition of the presumption in favour of jury trial, such as has been achieved by s 11 of the 2013 Act.

38 Arguably, one of the only cases to fail the serious harm test that may have been successful under the rules in Northern Ireland is that of Nwakama, Ihenakaram and O'Nwere $v$ Bartholomew Umeyor [2020] EWHC 3262 (QB). In Nwakama, the meaning of the words may have been judged to have an inherent tendency to cause harm to reputation, but the court's careful analysis of facts under s 1 revealed the statement was published only to a very small number of people, that it appeared no one believed the allegations, there was a retraction of the statement soon after publication, and the claimant's accounts on examination were found to be unconvincing and exaggerated [79]. Cf Coulter $v$ Sunday Newspapers Ltd [2016] NIQB 70 and Coulter $v$ Sunday Newspapers Ltd [2017] NICA 10. 
of the nature of defamation on social media, the decision in Foster $v$ Jessen, and the exercise the court was compelled to undertake to resolve the case, should assure plaintiffs in Northern Ireland that a serious harm test would still catch a great majority of defamatory statements that would be actionable under the old law and would only filter out a narrow band of cases on an equitable basis. 